\title{
A Novel Hybrid Model for $\mathrm{Cu}-\mathrm{Al}_{2} \mathrm{O}_{3} / \mathrm{H}_{2} \mathrm{O}$ Nanofluid Flow and Heat Transfer in Convergent/Divergent Channels
}

\author{
Umar Khan ${ }^{1}$, Adnan ${ }^{2}$, Naveed Ahmed ${ }^{3}{ }^{-}$, Syed Tauseef Mohyud-Din ${ }^{3}$, Dumitru Baleanu ${ }^{4,5,6}$, \\ Ilyas Khan ${ }^{7, *}$ and Kottakkaran Sooppy Nisar ${ }^{8}$ (i) \\ Department of Mathematics and Statistics, Hazara University, Mansehra 21120, Pakistan \\ Department of Mathematics, Mohi-ud-Din Islamic University, Nerian Sharif, AJ\&K, Trarkhel 12080, Pakistan \\ Department of Mathematics, Faculty of Sciences, Heavy Industries Taxila Education City University, \\ Taxila Cantt 47070, Pakistan \\ 4 Department of Mathematics, Cankaya University, Ankara 06790, Turkey \\ 5 Institute of Space Sciences, 077125 Magurele, Romania \\ 6 Department of Medical Research, China Medical University Hospital, China Medical University, \\ Taichung 404, Taiwan \\ 7 Faculty of Mathematics and Statistics, Ton Duc Thang University, Ho Chi Minh City 72915, Vietnam \\ 8 Department of Mathematics, College of Arts and Sciences, Wadi Aldawaser, 11991, Prince Sattam bin \\ Abdulaziz University, Wadi Aldawaser 11991, Saudi Arabia \\ * Correspondence: ilyaskhan@tdtu.edu.vn
}

Received: 3 March 2020; Accepted: 28 March 2020; Published: 3 April 2020

\begin{abstract}
In the present study, our aim is to present a novel model for the flow of hybrid nanofluids in oblique channels. Copper and aluminum oxide have been used to obtain a novel hybrid nanofluid. The equations that govern the flow of hybrid nanofluids have been transformed to a set of nonlinear equations with the implementation of self-similar variables. The resulting system is treated numerically by using coupled shooting and Runge-Kutta (R-K) scheme. The behavior of velocity and temperature is examined by altering the flow parameters. The cases for narrowing (convergent) and opening (divergent) channels are discussed, and the influence of various parameters on Nusselt number is also presented. To indicate the reliability of the study, a comparison is made that confirms the accuracy of the study presented.
\end{abstract}

Keywords: heat transfer; convergent/divergent channels; hybrid nanofluids; base fluid; numerical solution; Nusselt number

\section{Introduction}

Heat transfer in regular fluids can be improved passively by altering flow situation, different flow parameters (like convective boundary condition, partial slip, etc.), or by enhancing fluid thermal conductivity. To improve the heat transfer in fluids several theoretical techniques have been proposed. Thus, researchers believed that the thermal conductivity of carrier fluids can be improved by a colloidal suspension of nano- or larger-sized particles of metals and their oxides because liquids have less thermal conductivity compared to that of metals. Thus, numerous experimental and theoretical studies on the colloidal suspension of fluids and solid particles of metals have been conducted since the larger size of metal particles and density are not helpful in preventing the mixture of particles and fluids because the lack of stability of such a colloidal composition produces extra flow resistance. Hence, suspension of large-sized metal particles in the fluids has not been popular until now. 
The latest nanotechnology provides numerous ways to produce colloidal suspension of various metal particles, below $50 \mathrm{~nm}$ in size, in various common fluids. Earlier work in this direction was done by Choi [1] who adopted the term nanofluids. This newly developed class of fluids (nanofluids) opened a new researcher platform which proved very helpful in technological processes and industrial zones. Nanofluids can be considered as another class of heat transportation fluids because they provide exciting possibilities regarding heat transfer characteristics compared to that of regular liquids. Researchers expected that the presence of nano-sized metallic particles in conventional fluids has the best heat transfer properties. Diluted nanoparticles in numerous conventional fluids can alter fluid flow properties, especially heat transfer enhancement. In order to thermally improve fluids, numerous theoretical models for effective dynamic viscosity and effective thermal conductivity have been proposed. Significant research pertaining to nanofluids' thermal and physical characteristics is presented by Wang and Mujumdar [2].

Flow between oblique walls (also called Jeffery-Hamel flow) is a potential research direction. Initially Jeffery [3] and Hamel [4] explored such a flow, naming it the Jeffery-Hamel flow. Due to variety of applications of such flows, Jeffery and Hamel became very popular among the research community and researchers focused on the study of such flows. These applications comprised mechanical, environmental, chemical, and aerospace engineering. The applications of Jeffery-Hamel flow were also involved in biomedical sciences. For example, the flow of blood in veins and arteries is an example of Jeffery-Hamel flow. In light of these facts, researchers focused on the study of Jeffery-Hamel flow from various aspects and studied the behavior of fluid flow characteristics.

The flows of various fluid types between converging/diverging channels have been extensively studied. Recently, Adnan and colleagues $[5,6]$ investigated radiative flow regimes and the effects of cross diffusion for second grade fluids, respectively. The effects of stretchable walls and Lorentz forces play a significant role on fluid velocity and temperature. Mohyud-Din et al. [7] discussed the magnetohydrodynamic flow of incompressible fluid containing nano-sized metallic particles between nonparallel walls in the existence of stretching and shrinking. Noor et al. [8] explored the influence of thermophoretic parameters and presented graphical results for heat and mass transfer. Khan and co-workers [9] presented the remarkable effects of resistive heating on dissipative flow between convergent/divergent channels and encountered variations in the fluid velocity and temperature for variable magnetic fields. Muhammad and colleagues [10] described three-dimensional (3D) nanofluid flow in the existence of convective flow conditions, while in two separate studies, Hayat and colleagues [11,12] discussed the flow of Maxwell nanofluids and influence of carbon nanotubes, respectively. Sheikholeslami et al. (see [13-15]) discussed the flow of nanofluids in different geometries, while Bhatti et al. [13] presented the impact of imposed Lorentz forces in flow behavior over a shrinking sheet. Meanwhile, Bhatti and colleagues [14] and Rashidi and Abbas [15] investigated the behavior of fluid temperature due to effective Prandtl number and provided an analytical analysis of drug delivery, respectively. Additional studies [16-29] investigate flow and heat transfer enhancement in nanofluids and conventional fluids.

The phenomenon of heat transfer rate and shear stresses at the surface is of potential significance from engineering and industrial production perspectives. Therefore, the presented work will cover the results of the multiple parameters ingrained in the model.

The colloidal flow between opening and narrowing channels is interesting from a medical and engineering point of view. Therefore, the colloidal mixture of $\mathrm{Cu}-\mathrm{Al}_{2} \mathrm{O}_{3} / \mathrm{H}_{2} \mathrm{O}$ is contemplated and handled numerically. The main target of the analysis will to examine the impacts of multiple parameters on flow behavior, temperature, shear stresses at the wall surface, and heat transfer rate. 


\section{Materials and Methods}

\subsection{Model Formulation}

Time-independent flow of $\mathrm{Cu}-\mathrm{Al}_{2} \mathrm{O}_{3} / \mathrm{H}_{2} \mathrm{O}$ hybrid nanofluid is taken between two inclined plane walls. Fluid flow is due to a source or sink situated at the culmination of the channel. The angle between the walls is $2 \alpha$. Furthermore, flow is unidirectional and purely along the radial line. Due to this, only $u$ component of the velocity is responsible for the flow of the fluid. In addition, flow is of the symmetric type. Figure 1 demonstrates the physical theme of the hybrid nanofluid flow between convergent/divergent channels. The shape factors [30] of different nanoparticles, namely spherical, bricks, cylinder, platelets, and blades are depicted in Figure 2.

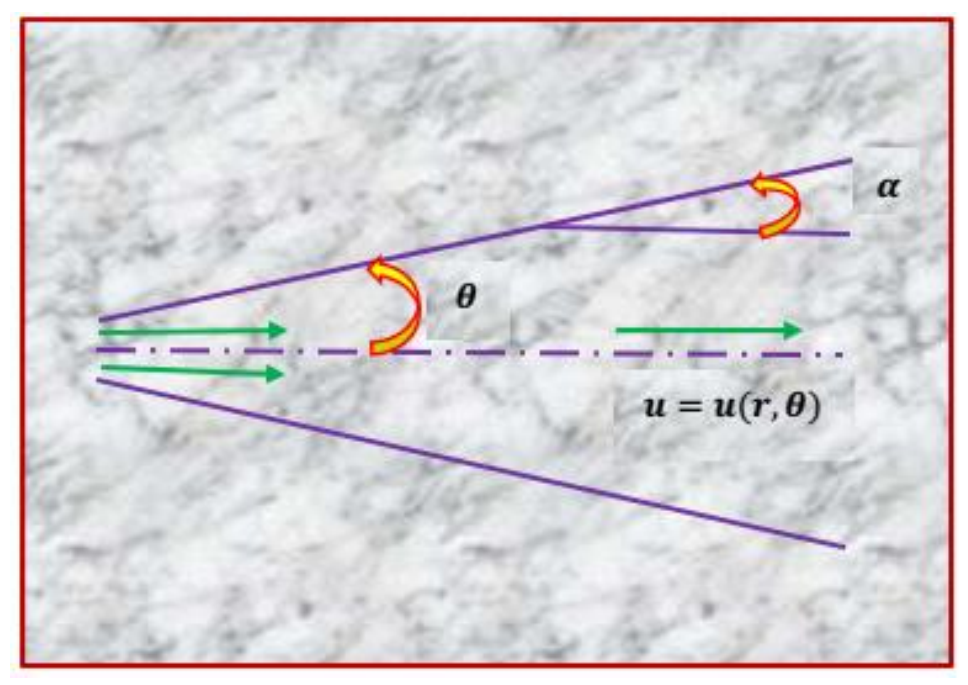

Figure 1. Pictorial view of flow configuration.

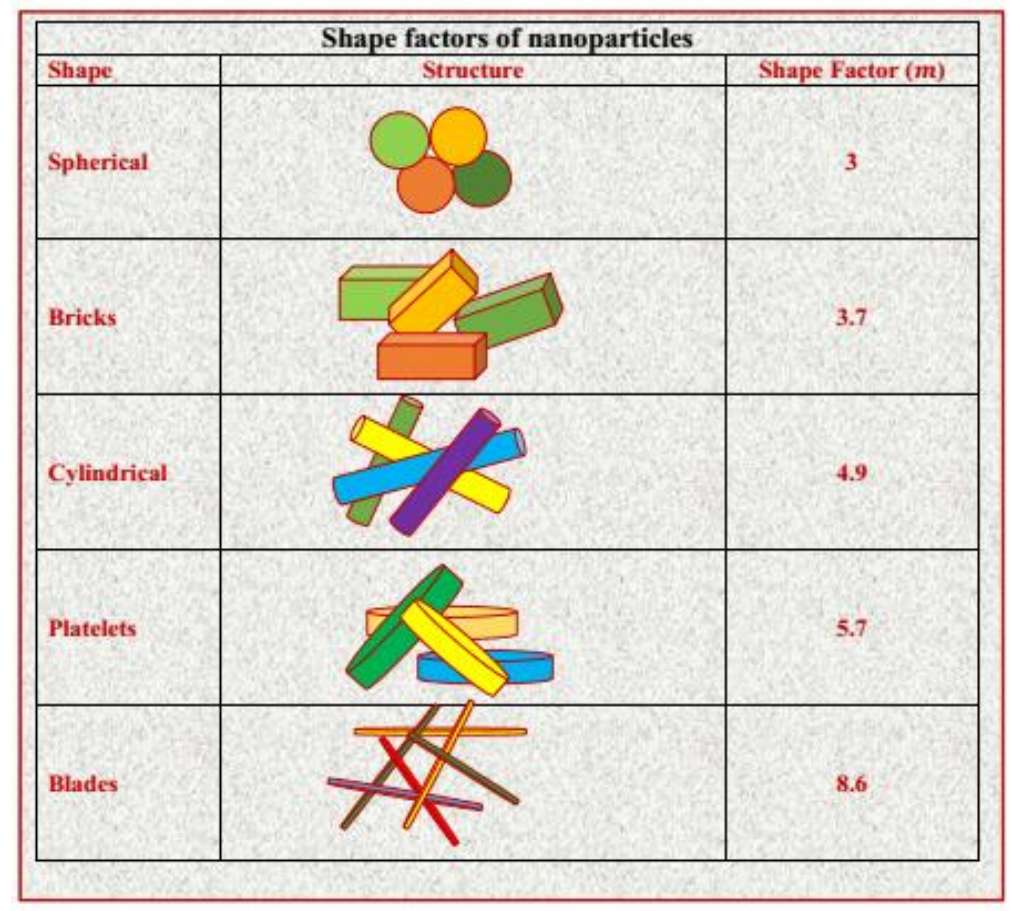

Figure 2. Shape factors of the nanoparticles. 
Governing equations that describe the flow of hybrid nanofluids in an oblique channel in the presence of viscous dissipation are as follows [31]:

$$
\begin{gathered}
r^{-1} \frac{\partial}{\partial r}(r u)=0 \\
\rho_{h n f}\left(u \frac{\partial u}{\partial r}\right)=-\frac{\partial p}{\partial r}+\mu_{h n f}\left(\frac{\partial^{2} u}{\partial r^{2}}+r^{-1} \frac{\partial u}{\partial r}+r^{-2} \frac{\partial^{2} u}{\partial \theta^{2}}-r^{-2} u\right) \\
-\frac{1}{r \rho_{h n f}} \frac{\partial p}{\partial \theta}+\frac{2 r^{-2} \mu_{h n f}}{\rho_{h n f}} \frac{\partial u}{\partial \theta}=0 \\
\left(\rho C_{p}\right)_{h n f} u \frac{\partial T}{\partial r}=k_{h n f}\left(\frac{\partial^{2} T}{\partial r^{2}}+r^{-1} \frac{\partial T}{\partial r}+r^{-2} \frac{\partial^{2} T}{\partial \theta^{2}}\right)+\mu_{h n f}\left(4\left(\frac{\partial u}{\partial r}\right)^{2}+r^{-2}\left(\frac{\partial u}{\partial \theta}\right)^{2}\right)
\end{gathered}
$$

Supporting conditions at the wall and central line are:

$$
\text { At } \theta=0
$$

$$
\frac{\partial u}{\partial \theta}=0, \frac{\partial T}{\partial \theta}=0, u=U
$$

At $\theta=\alpha$

$$
u=0, T=T_{w}
$$

where $T_{w}$ is temperature at the wall; $U$ is the velocity at the central line; $\rho h n f, \mu h n f,\left(\rho C_{p}\right)_{h n f}$ show effective density, dynamic viscosity, and heat capacitance, respectively; $p$ denotes the pressure; and $k_{h n f}$ is the hybrid thermal conductance. Table 1 presenting the effective models for nanofluids characteristics.

Table 1. Effective models for hybrid nanofluid characteristics.

\begin{tabular}{ccc}
\hline Properties & Nanofluid & Hybrid Nanofluid \\
\hline Density & $\rho_{n f}=\left\{(1-\phi)+\frac{\phi \rho_{s}}{\rho_{f}}\right\} \rho_{f}$ & $\left.\rho_{h n f}=\left[\left(1-\phi_{2}\right)\left\{1-\phi_{1}\right)+\frac{\phi_{1} \rho_{s 1}}{\rho_{f}}\right\}+\frac{\phi_{2} \rho_{s 2}}{\rho_{f}}\right] \rho_{f}$ \\
Heat capacity & $\left(\rho C_{p}\right)_{n f}=$ & $\left(\rho C_{p}\right)_{h n f}=$ \\
Viscosity & $\mu_{n f}=\mu_{f}(1-\phi)^{-2.5}$ & $\left(\rho C_{p}\right)_{f}+\phi\left(\rho C_{p}\right)_{s}$
\end{tabular}

where, $\beth=m-1$ and thermophysical properties [32] are tabulated in Table 2.

Table 2. Thermo-physical characteristics.

\begin{tabular}{cccc}
\hline Characteristics & $\mathbf{H}_{2} \mathbf{O}$ & $\mathbf{A l}_{2} \mathbf{O}_{3}$ & $\mathbf{C u}$ \\
\hline$\rho\left(k g m^{-3}\right)$ & 997.0 & 3970 & 8933 \\
$C_{p}(\mathrm{~J} / \mathrm{kgK})$ & 4180 & 765 & 385 \\
$K(\mathrm{~W} / \mathrm{mK})$ & 0.6071 & 40 & 400 \\
\hline
\end{tabular}

The following models used for hybrid nanofluids are depicted in Table 1 [32].

The particular values of density, heat capacity and thermal conductivity of the host liquid and tiny particles defined in Table 2.

For a particular flow problem, the feasible similarity transformations are defined as:

$$
F(\eta)=\frac{f(\theta)}{f_{\max }}, \Theta=\frac{T}{T_{w}} \text { and } \eta=\frac{\theta}{\alpha}
$$


where

$$
f(\theta)=r u(r, \theta)
$$

After entreating the suitable derivatives from self-similar parameters in Equations (2) and (3) and also using the suitable partial differentiation of similarity variables, governing partial differential equations were reduced into the following nonlinear flow model:

$$
\begin{gathered}
F^{\prime \prime \prime}+4 \alpha^{2} F^{\prime}+\frac{2 \alpha \operatorname{Re}\left[\left(1-\phi_{2}\right)\left\{\left(1-\phi_{1}\right)+\frac{\phi_{1} \rho_{s 1}}{\rho_{f}}\right\}+\frac{\phi_{2} \rho_{s 2}}{\rho_{f}}\right]\left(1-\phi_{1}\right)^{2.5}}{\left(1-\phi_{2}\right)^{-2.5}} F F^{\prime}=0 \\
\Theta^{\prime \prime}+\frac{\operatorname{Pr} E c}{\left(1-\phi_{1}\right)^{2.5}\left(1-\phi_{2}\right)^{2.5} k_{h n f}}\left(4 \alpha^{2} F^{2}+F^{2}\right)=0
\end{gathered}
$$

In Equations (9) and (10), $\alpha$ denotes converging/diverging parameters; Pr is the Prandtl number; and $E_{c}$ is the Eckert number. These parameters are:

$$
\operatorname{Pr}=\frac{U^{2}}{C_{p} T_{w}}, E c=\frac{\mu_{f} C_{p}}{k_{f}}
$$

Further, the Reynold's number is defined in the following manner:

$$
R e=\frac{f}{v}=\frac{U \alpha r}{v}\left(\begin{array}{c}
\text { Diverging channel }: \alpha>0, U>0 \\
\text { Convergent channel }: \alpha<0, U<0
\end{array}\right)
$$

The suitable boundary conditions in dimensionless form for velocity and temperature are as follows:

$$
\begin{gathered}
F\left(\eta_{=0}\right)=1, F\left(\eta_{=1}\right)=0 \text { and } F^{\prime}\left(\eta_{=0}\right)=0 \\
\Theta \prime\left(\eta_{=0}\right)=0, \Theta\left(\eta_{=1}\right)=1
\end{gathered}
$$

The nondimensional expressions for shear stress and local heat transfer rate are:

$$
\begin{gathered}
\operatorname{ReC}_{f}=\frac{1}{\left(1-\phi_{1}\right)^{2.5}\left(1-\phi_{2}\right)^{2.5}} F_{\prime}(1) \\
\alpha N u=-\frac{k_{h n f}}{k_{f}} \Theta \prime(1)
\end{gathered}
$$

\subsection{Solution of the Problem}

Under consideration hybrid nanofluid model is nonlinear for such model, it is tedious performed closed form of solution or not even exist. Thus, we focused on numerical treatment of the model. For this cause, we adopted Runge-Kutta scheme [26-28]. In order to apply afore said technique, firstly reduce the present model into a system of first ordinary differential equations (ODEs). The following substitutions were considered for this purpose.

$$
y_{1}=F, y_{2}=F^{\prime}, y_{3}=F^{\prime \prime}, y_{4}=\Theta, y_{5}=\Theta \prime
$$

The particular model can be written as:

$$
F^{\prime \prime \prime}=-4 \alpha^{2} F^{\prime}-\frac{2 \alpha \operatorname{Re}\left[\left(1-\phi_{2}\right)\left\{\left(1-\phi_{1}\right)+\frac{\phi_{1} \rho_{s 1}}{\rho_{f}}\right\}+\frac{\phi_{2} \rho_{s 2}}{\rho_{f}}\right]\left(1-\phi_{1}\right)^{2.5}}{\left(1-\phi_{2}\right)^{-2.5}} F F^{\prime}
$$




$$
\Theta^{\prime \prime}=-\frac{\operatorname{PrEc}}{\left(1-\phi_{1}\right)^{2.5}\left(1-\phi_{2}\right)^{2.5} k_{h n f}}\left(4 \alpha^{2} F^{2}+F^{2}\right)
$$

Now, entreating the described transformations we have:

$$
\left[\begin{array}{l}
y_{1}^{\prime} \\
y_{2}^{\prime} \\
y_{3}^{\prime} \\
y_{4}^{\prime} \\
y_{5}^{\prime}
\end{array}\right]=\left[\begin{array}{c}
y_{2} \\
y_{3} \\
-4 \alpha^{2} y_{2} \frac{2 \alpha R e\left[\left(1-\phi_{2}\right)\left\{\left(1-\phi_{1}\right)+\frac{\phi_{1} \rho_{s 1}}{\rho_{f}}\right\}+\frac{\phi_{2} \rho_{s 2}}{\rho_{f}}\right]\left(1-\phi_{1}\right)^{2.5}}{\left(1-\phi_{2}\right)^{-2.5}} y_{1} y_{2} \\
-\frac{y_{5}}{\left(1-\phi_{1}\right)^{2.5}\left(1-\phi_{2}\right)^{2.5} k_{h n f}}\left(4 \alpha^{2} y_{1}^{2}+y_{2}^{2}\right)
\end{array}\right]
$$

The corresponding initial conditions are in the following way.

$$
\left[\begin{array}{l}
y_{1} \\
y_{2} \\
y_{3} \\
y_{4} \\
y_{5}
\end{array}\right]=\left[\begin{array}{l}
1 \\
0 \\
1 \\
0 \\
1
\end{array}\right]
$$

Now, the model is treated by Mathematica 10.0.

\section{Graphical Results and Discussion}

The flow quantities altered the fluid flow behavior effectively over the domain of interest. These parameters are converging/diverging parameter $\alpha$, the volumetric fraction of the nanoparticles, Reynolds number $R e$, and Eckert number $E c$. The velocity and thermal field are decorated graphically in the region $-1 \leq \eta \leq 1$. The cases of $\mathrm{Cu} / \mathrm{H}_{2} \mathrm{O}$ and $\mathrm{Cu}-\mathrm{Al}_{2} \mathrm{O}_{3} / \mathrm{H}_{2} \mathrm{O}$ are presented for both converging $(\alpha<0)$ and diverging $(\alpha>0)$ parameters, respectively. The influence of the aforementioned physical quantities are incorporated in Figures 3-12.

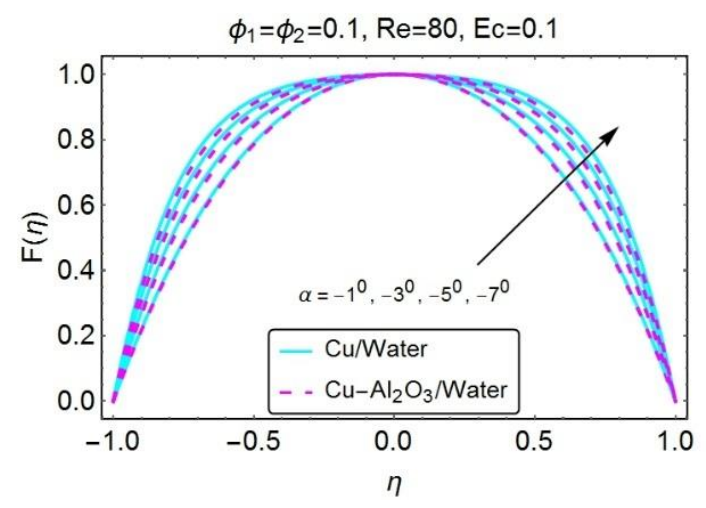

(a)

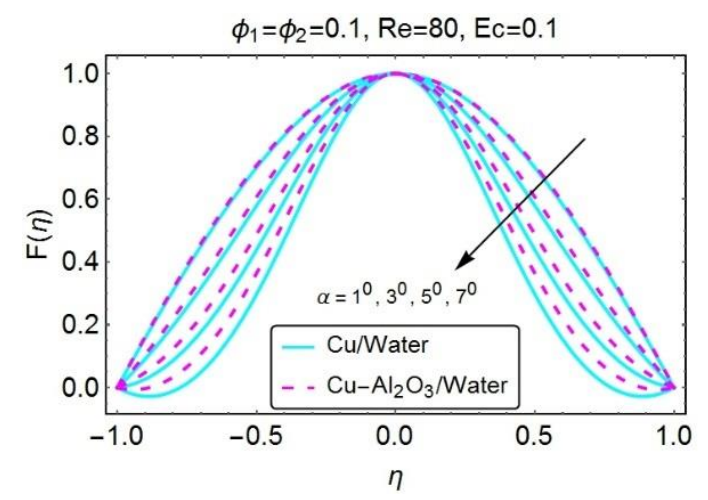

(b)

Figure 3. Stimulus of $\alpha$ on $F(\eta)$ : (a) convergent case (b) divergent channel. 


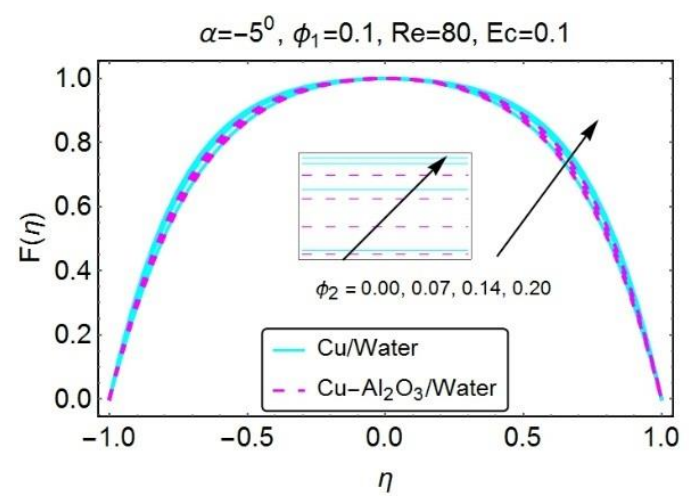

(a)

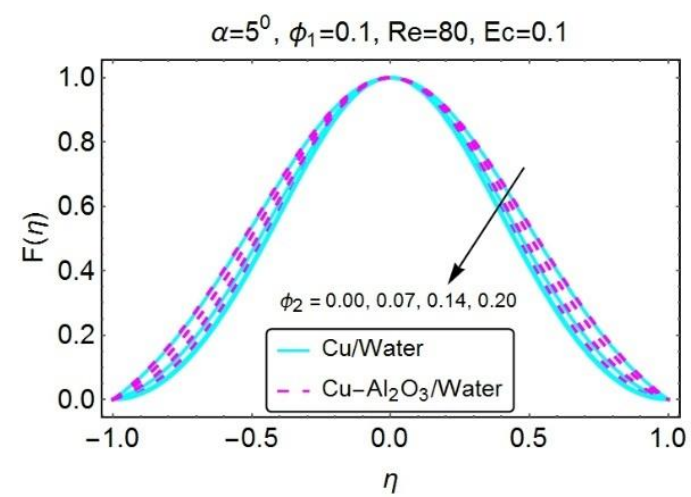

(b)

Figure 4. Stimulus of $\phi_{2}$ on $F(\eta)$ : (a) convergent case and (b) divergent channel.

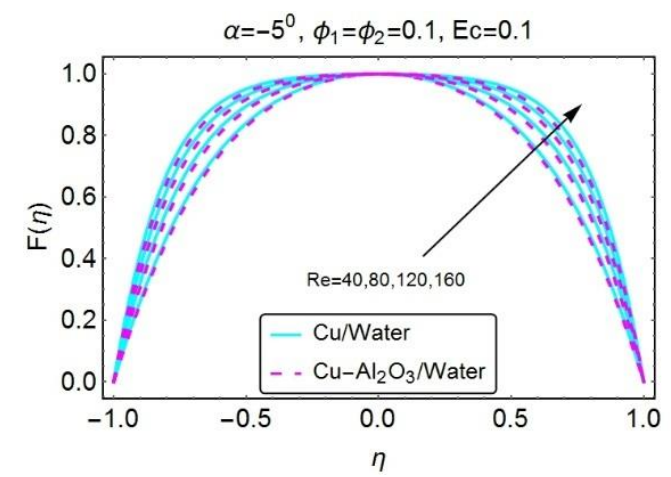

(a)

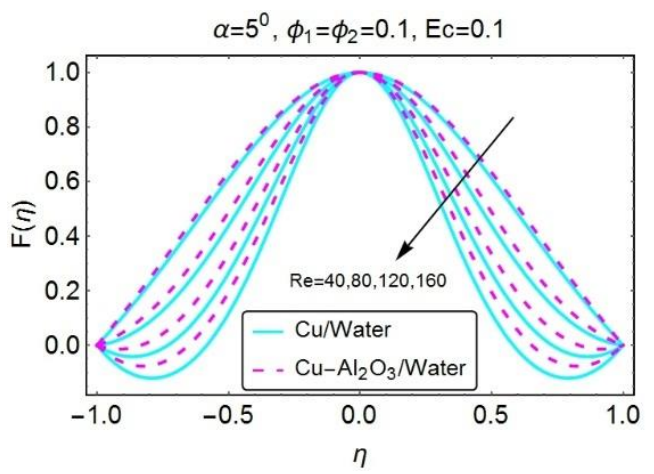

(b)

Figure 5. Stimulus of $\operatorname{Re}$ on $F(\eta)$ : (a) convergent case and (b) divergent channel.

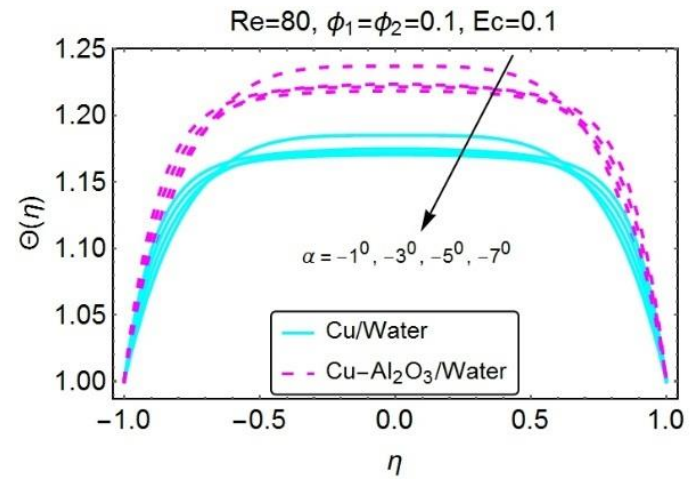

(a)

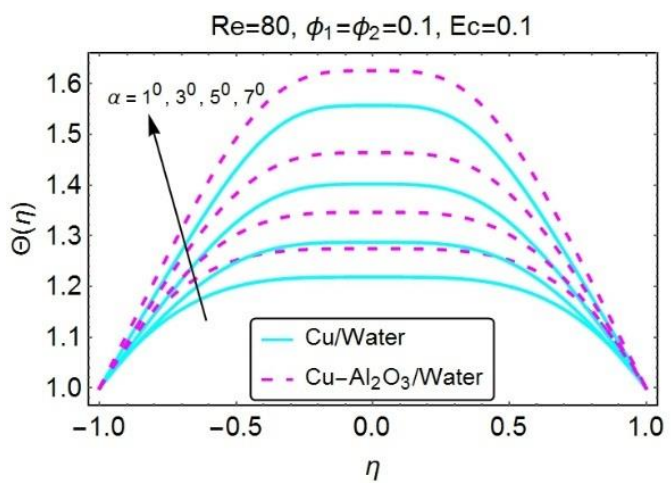

(b)

Figure 6. Stimulus of $\alpha$ on $\Theta(\eta)$ : (a) convergent case and (b) divergent channel. 


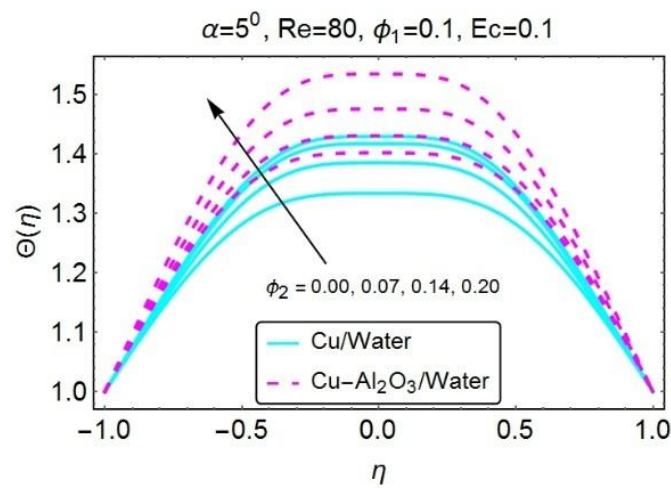

(a)

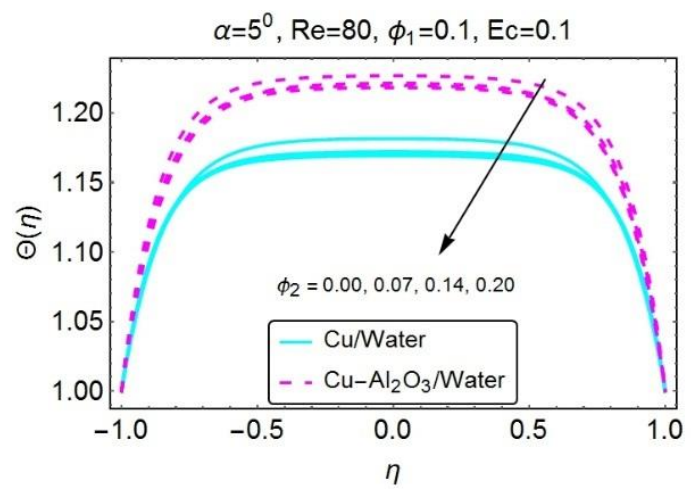

(b)

Figure 7. Stimulus of $\phi_{2}$ on $\Theta(\eta)$ : (a) convergent case and (b) divergent channel.

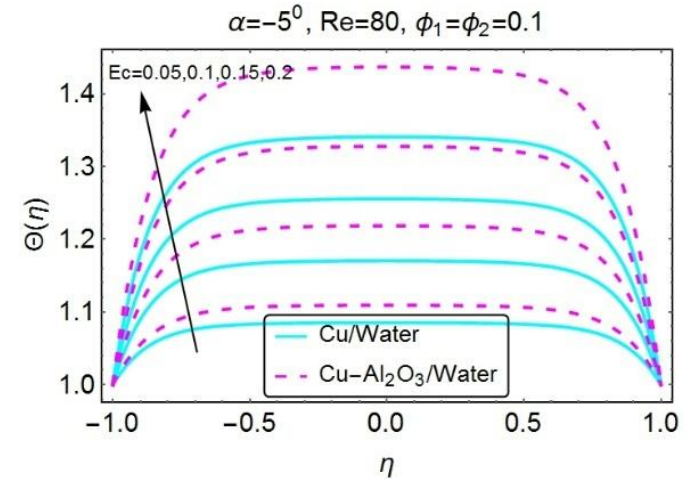

(a)

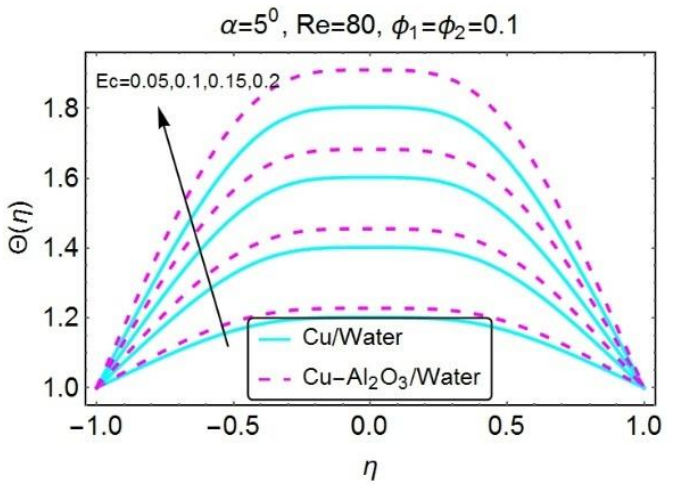

(b)

Figure 8. Stimulus of $E c$ on $\Theta(\eta)$ : (a) convergent case and (b) divergent channel.

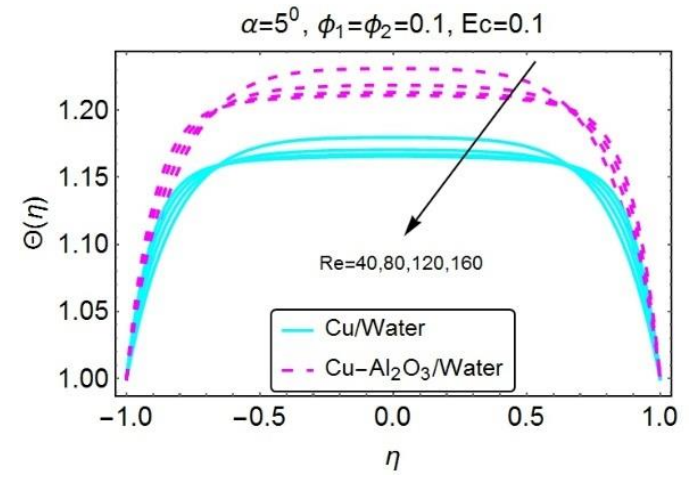

(a)

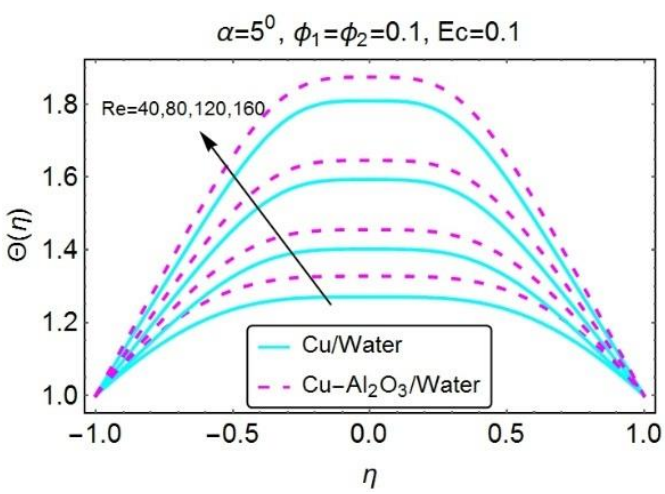

(b)

Figure 9. Stimulus of $\operatorname{Re}$ on $\Theta(\eta)$ : (a) convergent case and (b) divergent channel. 


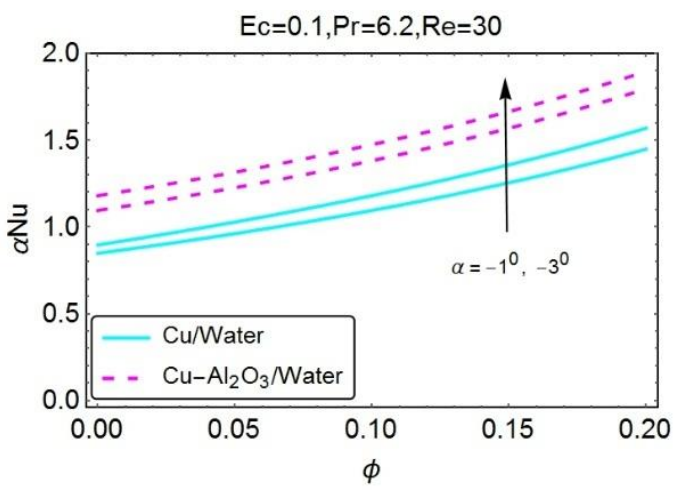

(a)

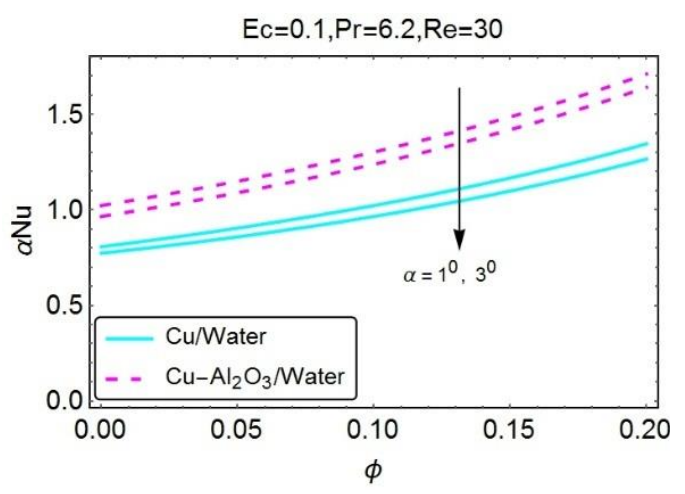

(b)

Figure 10. Stimulus of $\alpha$ on $\alpha \mathrm{Nu}$ : (a) convergent case and (b) divergent channel.

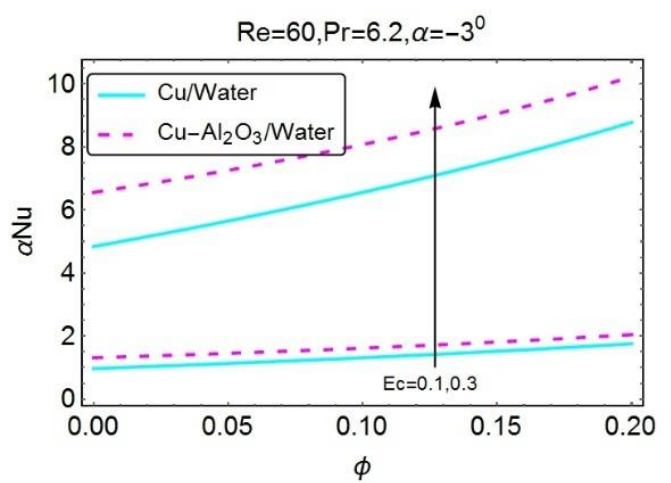

(a)

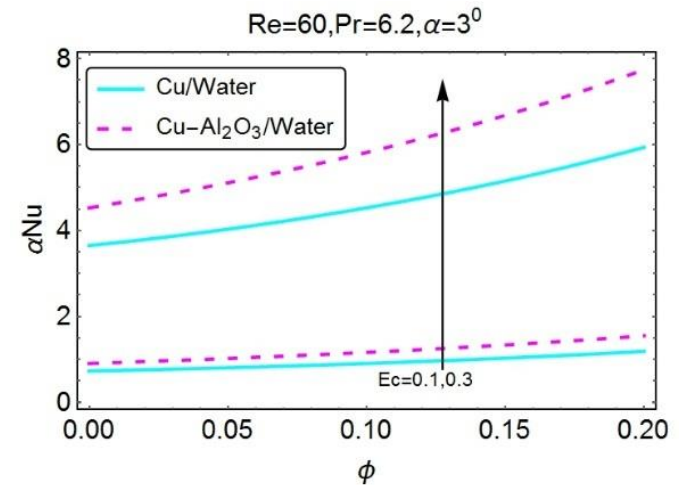

(b)

Figure 11. Stimulus of $E c$ on $\alpha \mathrm{Nu}$ : (a) convergent case and (b) divergent channel.

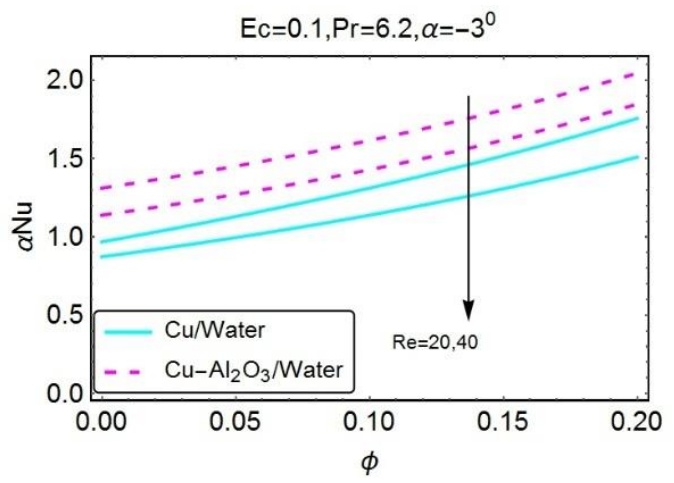

(a)

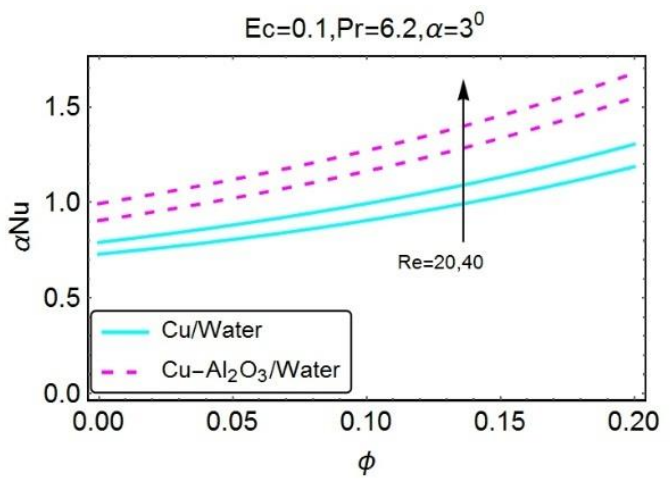

(b)

Figure 12. Stimulus of $R e$ on $\alpha \mathrm{Nu}$ : (a) convergent case and (b) divergent channel.

The influence of opening (diverging case) and narrowing (converging case) channels on the fluid velocity $F(\eta)$ are incorporated in Figure $3 \mathrm{a}, \mathrm{b}$, respectively. A very fascinating behavior of converging/diverging parameter $\alpha$ is observed. It can be seen that when the channel walls become narrow, the fluid flowing area between the walls decreases and as a result fluid velocity starts increasing. The variations in fluid velocity above $(0 \leq \eta \leq 1)$ and below $(-1 \leq \eta \leq 0)$ the central line are similar because the flow is of a symmetric nature. For $\mathrm{Cu} /$ water and $\mathrm{Cu}-\mathrm{Al}_{2} \mathrm{O}_{3} / \mathrm{H}_{2} \mathrm{O}$ almost similar velocity behavior is examined. At the middle part of the channel $(\eta=0)$ the velocity field coincides for both $\mathrm{Cu} /$ water and $\mathrm{Cu}-\mathrm{Al}_{2} \mathrm{O}_{3} / \mathrm{H}_{2} \mathrm{O}$ nanofluids. It is observed that fluid velocity increases very slowly near the upper and lower portion of the channel. The converging parameter $\alpha$ affects the velocity field significantly in the area $-0.5 \leq \eta<0$ and $0<\eta \leq 0.5$. The influence of increasing $\alpha$ on the velocity profile 
$F(\eta)$ is depicted in Figure 3b. As for the opening channel (diverging case), the flowing area increases which causes a decrease in fluid motion. For $\mathrm{Cu}$ /water, velocity drops promptly in comparison with $\mathrm{Cu}-\mathrm{Al}_{2} \mathrm{O}_{3} / \mathrm{H}_{2} \mathrm{O}$. The pattern of fluid velocity is parabolic at the middle of the channel. Near the upper and lower channel walls, the velocity of both $\mathrm{Cu} /$ water and $\mathrm{Cu}-\mathrm{Al}_{2} \mathrm{O}_{3} / \mathrm{H}_{2} \mathrm{O}$ decreases very rapidly. Near the walls, back flow produces for higher $\alpha$.

For flow characteristics of nanofluids, the volumetric fraction plays the role of back bone. The influence of this important parameter on fluid motion is portrayed in Figure 4 . It noticed that the convergent channel volumetric fraction favors the fluid motion, but these variations are almost inconsequential for $\mathrm{Cu}$ /water and $\mathrm{Cu}-\mathrm{Al}_{2} \mathrm{O}_{3} / \mathrm{H}_{2} \mathrm{O}$. A more flattened velocity profile is observed in the middle of the channel. In the case of the opening channel (Figure $4 \mathrm{~b}$ ), the volumetric fraction opposes the fluid motion. In the locality of the center line, the velocity profile is more steepened and almost similar for $\mathrm{Cu}$ /water and $\mathrm{Cu}-\mathrm{Al}_{2} \mathrm{O}_{3} / \mathrm{H}_{2} \mathrm{O}$. For $\mathrm{Cu}$ /water, the reduced velocity is quite rapid as compared to $\mathrm{Cu}-\mathrm{Al}_{2} \mathrm{O}_{3} / \mathrm{H}_{2} \mathrm{O}$.

The dimensionless physical quantities, namely Reynold's number, which is the ratio of inertial to viscous forces, is a key point to analyze whether the flow is laminar or turbulent. The effects of this important physical parameter in the flow regimes are demonstrated in Figure $5 \mathrm{a}, \mathrm{b}$ for converging and diverging cases, respectively. For the convergent channel, the positive influence of Reynold's number on the fluid motion is investigated. Along the middle line of the channel influences are prominent. The nanofluid $\left(\mathrm{Cu} /\right.$ water and $\left.\mathrm{Cu}-\mathrm{Al}_{2} \mathrm{O}_{3} / \mathrm{H}_{2} \mathrm{O}\right)$ shows almost negligible increments in the velocity field. In Figure 5b, variations in Reynolds number lead to a very cleared velocity profile. It can be seen that increasing Reynold's number in a diverging channel produces more back flow near both the upper and lower channel walls. More back flow near the walls are examined in the case of $\mathrm{Cu} / \mathrm{H}_{2} \mathrm{O}$.

The effects of $\alpha$, Eckert number, and Reynold's number are shown in Figures 6-9. Figure 6 investigates the opposite behavior of the thermal field. It is clear that for negative $\alpha$, fluid temperature decreases in the region $-0.5 \leq \eta \leq 0$ and in $0 \leq \eta \leq 0.5$, the temperature profile starts decelerating. In the case of $\mathrm{Cu}$ /water, rapid reduction in the temperature occurs. The reverse alterations are examined from $-1.0 \leq \eta \leq-0.5$ and $0.5 \leq \eta \leq 1.0$. On the other hand, the opening channel favors the fluid temperature. The temperature of $\mathrm{Cu}-\mathrm{Al}_{2} \mathrm{O}_{3} / \mathrm{H}_{2} \mathrm{O}$ increases very rapidly. In addition, the thermal field of water containing copper nanoparticles increases, but upturns in the temperature are quite slow in comparison with of $\mathrm{Cu}-\mathrm{Al}_{2} \mathrm{O}_{3} / \mathrm{H}_{2} \mathrm{O}$ nanofluid. Beyond the region $-1.0 \leq \eta \leq-0.5$ and $0.5 \leq \eta \leq 1.0$, increase in temperature slows down.

The influence of volumetric fraction on the fluid temperature for converging and diverging channels is depicted in Figure 7a,b, respectively. It is noted that the volumetric fraction $\phi_{2}$ shows reverse variations in the fluid temperature $\Theta(\eta)$. For nanoparticles of higher volume fraction, temperature starts to decrease. Decreasing effects of $\phi_{2}$ are quite prominent in the portion $-0.5 \leq \eta \leq 0.5$. Fluid near the channel walls shows almost negligible variations in the temperature for both $\mathrm{Cu} / \mathrm{water}$ and $\mathrm{Cu}-\mathrm{Al}_{2} \mathrm{O}_{3} / \mathrm{H}_{2} \mathrm{O}$ nanofluids, and temperature reduction is very rapid as compared to that of $\mathrm{Cu}-\mathrm{Al}_{2} \mathrm{O}_{3} / \mathrm{H}_{2} \mathrm{O}$ nanofluid. In the case of converging channel (Figure 7a), the volume fraction of the nanoparticles favors the fluid temperature. At the middle line and in the locality of the middle line, fluid temperature increases quickly and for $\mathrm{Cu}-\mathrm{Al}_{2} \mathrm{O}_{3} / \mathrm{H}_{2} \mathrm{O}$, increasing behavior of dimensionless temperature $\Theta(\eta)$ is very rapid.

Very fascinating behavior of Eckert number $E c$ on the temperature field was observed from $-1.0 \leq \eta \leq 1.0$ for opening and narrowing walls. These effects are demonstrated in Figure 8a,b, respectively. In the presence of Eckert number, temperature of $\mathrm{Cu} /$ water and $\mathrm{Cu}-\mathrm{Al}_{2} \mathrm{O}_{3} / \mathrm{H}_{2} \mathrm{O}$ nanofluids increases very clearly. It was examined that for $\alpha<0$ and $\alpha>0$, Eckert number favors the temperature profile. In converging channel, the temperature field is flatter in the vicinity of the middle line of the channel in comparison with the opening case. The variations in the fluid temperature due to increasing Reynold's number Re are depicted in Figure 9a,b, respectively for narrowing and opening channels. It was examined that Reynold's number opposes the fluid temperature in the convergent case. In the divergent case, fluid temperature (for both $\mathrm{Cu} /$ water and $\mathrm{Cu}-\mathrm{Al}_{2} \mathrm{O}_{3} / \mathrm{H}_{2} \mathrm{O}$ ) increases sharply. 
Alterations in heat transfer rate are of great importance due to many industrial and technological uses. The various flow parameters play a significant role in local heat transfer rate (Figures 10-12). From Figure 10 it is obvious that more heat transfers at the walls for the narrowing channel. For the diverging case these influences reverse. Water containing $\mathrm{Cu}-\mathrm{Al}_{2} \mathrm{O}_{3}$ has the capability to transfer more heat at the channel walls compared to that of $\mathrm{Cu} /$ water. On the other hand, Eckert number favors the heat transfer rate in both opening and narrowing channels. These effects are demonstrated in Figure 11a,b, respectively. Further, Reynold's number affects the heat transfer rate reversely in both situations as shown in Figure 12.

Tables 3 and 4 compare the current results with existing literature under certain conditions for $-F^{\prime \prime}(0)$. For $\phi \_1=\phi \_2=0$, our flow model transformed into the model of conventional fluids and our results are parallel to existing ones which confirms the reliability of the study.

Table 3. Comparison for $-F^{\prime \prime}(0)$ in narrowing case.

\begin{tabular}{cccccc}
\hline \multicolumn{5}{c}{$\alpha=-5^{\circ}, \phi_{1}=\phi_{2}=0$} \\
\hline $\boldsymbol{R} \boldsymbol{e}$ & Present & {$[33]$} & [34] & [35] & [6] \\
\hline 10 & 1.784546 & 1.784546 & 1.784547 & 1.784547 & 1.784546 \\
\hline 30 & 1.413692 & 1.413692 & 1.413692 & 1.413692 & 1.413692 \\
\hline 50 & 1.121989 & 1.121989 & 1.121989 & 1.121989 & 1.121989 \\
\hline
\end{tabular}

Table 4. Comparison for $-F^{\prime \prime}(0)$ in opening case.

\begin{tabular}{cccccc}
\hline \multicolumn{5}{c}{$\alpha=-5^{\circ}, \phi_{\mathbf{1}}=\phi_{\mathbf{2}}=0$} \\
\hline $\boldsymbol{R} \boldsymbol{e}$ & Present & {$[33]$} & {$[34]$} & {$[35]$} & {$[6]$} \\
\hline 20 & 2.527192 & 2.527192 & 2.527192 & 2.527192 & 2.527192 \\
\hline 60 & 3.942140 & 3.942140 & 3.942140 & 3.942140 & 3.942140 \\
\hline 100 & 5.869165 & 5.869165 & 5.869165 & 5.869165 & 5.869165 \\
\hline
\end{tabular}

\section{Conclusions}

The colloidal hybrid flow regimes between the opening and narrowing channels are significant from medical and industrial perspectives. Therefore, $\mathrm{Cu}-\mathrm{Al}_{2} \mathrm{O}_{3} / \mathrm{H}_{2} \mathrm{O}$ is contemplated between the particular geometry. For mathematical treatment of the model, the R-K technique was adopted and painted significant results for multiple parameters. It was detected that for multiple $R e$ values, the velocity declines abruptly and back flow is detected near the walls. The velocity enhances for high fraction factor and $R e$ in narrowing flow situations. For more dissipative colloidal mixture, the temperature abruptly enhances for opening flow situation. A decline in the heat transfer rate is detected for $\alpha$ and Re in highly dissipative cases for opening and narrowing cases. A comparison between the presented results with scientific literature confirmed the reliability of the analysis.

Author Contributions: Conceptualization, U.K.; mathematical analysis, A.; results discussion, N.A.; supervising and validating the results, S.T.M.-D.; funding the work, D.B., I.K., and K.S.N. All authors have read and agreed to the published version of the manuscript.

Funding: This research received no external funding.

Conflicts of Interest: The authors declare no conflicts of interest.

\section{References}

1. Choi, S. Enhancing Thermal Conductivity of Fluids with Nanoparticles in Developments and Applications of Non-Newtonians Flows. ASME J. Heat Trans. 1995, 66, 99-105.

2. Wang, X.Q.; Mujumdar, A.S. A Review on Nanofluids Part-I: Theoretical and Numerical Investigations. Bra. J. Chem. Eng. 2008, 25, 613-630. [CrossRef] 
3. Jeffery, G.B. The two-dimensional steady motion of a viscous fluid. Phil. Mag. Ser. 1915, 29, 455-465. [CrossRef]

4. Hamel, G. Spiralformige Bewgungen zaher Flussigkeiten. Jahresber. Deutsch. Math.-Ver. 1916, 25, 34-60.

5. Adnan; Asadullah, M.; Khan, U.; Ahmed, N.; Mohyud-Din, S.T. Analytical and numerical investigation of thermal radiation effects on flow of viscous incompressible fluid with stretchable convergent/divergent channels. J. Mol. Liq. 2016, 224, 768-775. [CrossRef]

6. Adnan; Khan, U.; Ahmed, N.; Mohyud-Din, S.T. Thermo-diffusion and diffusion-thermo effects on flow of second grade fluid between two inclined plane walls. J. Mol. Liq. 2016, 224, 1074-1082. [CrossRef]

7. Mohyud-Din, S.T.; Khan, U.; Ahmed, N.; Hassan, S.M. Magnetohydrodynamic Flow and Heat Transfer of Nanofluids in Stretchable Convergent/Divergent Channels. Appl. Sci. 2015, 5, 1639-1664. [CrossRef]

8. Noor, N.F.M.; Abbasbandy, S.; Hashim, I. Heat and mass transfer of thermophoretic MHD flow over an inclined radiate isothermal permeable surface in the presence of heat source/sink. Int. J. Heat Mass Transf. 2012, 55, 2122-2128. [CrossRef]

9. Khan, U.; Adnan; Asadullah, M.; Ahmed, N.; Mohyud-Din, S.T. Influence of Joule Heating and Viscous Dissipation on MHD Flow and Heat Transfer of Viscous Fluid in Converging/Diverging Stretchable Channels. J. Nanofluids 2017, 6, 254-263. [CrossRef]

10. Muhammad, T.; Alsaedi, A.; Hayat, T.; Shehzad, S.A. A revised model for Darcy-Forchheimer three-dimensional flow of nanofluid subject to convective boundary condition. Results Phys. 2017, 7, 2791-2797. [CrossRef]

11. Hayat, T.; Muhammad, T.; Mustafa, M.; Alsaedi, A. An optimal study for three-dimensional flow of Maxwell nanofluid subject to rotating frame. J. Mol. Liq. 2017, 229, 541-547. [CrossRef]

12. Hayat, T.; Ahmed, S.; Muhammad, T.; Alsaedi, A. Modern aspects of homogeneous-heterogeneous reactions and variable thickness in nanofluids through carbon nanotubes. Phys. E Low-Dimens. Syst. Nanostruct. 2017, 94, 70-77. [CrossRef]

13. Bhatti, M.M.; Abbas, M.A.; Rashidi, M.M. A robust numerical method for solving stagnation point flow over a permeable shrinking sheet under the influence of MHD. Appl. Math. Comput. 2018, 316, 381-389. [CrossRef]

14. Bhatti, M.M.; Rashidi, M.M.; Abbas, M.A. Analytic Study of Drug Delivery in Peristaltically Induced Motion of Non-Newtonian Nanofluid. J. Nanofluids 2016, 5, 920-927. [CrossRef]

15. Rashidi, M.M.; Abbas, M.A. Effect of Slip Conditions and Entropy Generation Analysis with an Effective Prandtl Number Model on a Nanofluid Flow through a Stretching Sheet. Entropy 2017, 19, 414. [CrossRef]

16. Sheikholeslami, M.; Sadoughi, M. Simulation of CuO-water nanofluid heat transfer enhancement in presence of melting surface. Int. J. Heat Mass Transf. 2018, 116, 909-919. [CrossRef]

17. Sheikholeslami, M.; Rokni, H.B. Simulation of nanofluid heat transfer in presence of magnetic field: A review. Int. J. Heat Mass Transf. 2017, 115, 1203-1233. [CrossRef]

18. Sheikholeslami, M. Influence of magnetic field on nanofluid free convection in an open porous cavity by means of Lattice Boltzmann method. J. Mol. Liq. 2017, 234, 364-374. [CrossRef]

19. Sheikholeslami, M.; Rashidi, M.M. Non-uniform magnetic field effect on nanofluid hydrothermal treatment considering Brownian motion and thermophoresis effects. J. Braz. Soc. Mech. Sci. Eng. 2015, 38, 1171-1184. [CrossRef]

20. Qing, J.; Bhatti, M.M.; Abbas, M.A.; Rashidi, M.M.; Ali, M. Entropy Generation on MHD Casson Nanofluid Flow over a Porous Stretching/Shrinking Surface. Entropy 2016, 18, 123. [CrossRef]

21. Mabood, F.; Shateyi, S.; Rashidi, M.M.; Momoniat, E.; Freidoonimehr, N. MHD stagnation point flow heat and mass transfer of nanofluids in porous medium with radiation, viscous dissipation and chemical reaction. Adv. Powder Technol. 2016, 27, 742-749. [CrossRef]

22. Sheikholeslami, M. Magnetohydrodynamic nanofluid forced convection in a porous lid driven cubic cavity using Lattice Boltzmann method. J. Mol. Liq. 2017, 231, 555-565. [CrossRef]

23. Sheikholeslami, M. CuO-water nanofluid free convection in a porous cavity considering Darcy law. Eur. Phys. J. Plus 2017, 132, 55. [CrossRef]

24. Nasiri, M.; Rashidi, M.M. Effect of Magnetic Field on Hydrodynamic Behavior. Available online: https://www.ukessays.com/essays/engineering/effect-magnetic-field-hydrodynamic-7437.php?vref=1 (accessed on 30 March 2020). 
25. Khalili, S.; Tamim, H.; Khalili, A.; Rashidi, M.M. Unsteady convective heat and mass transfer in pseudoplastic nanofluid over a stretching wall. Adv. Powder Tech. 2015, 26, 1319-1326. [CrossRef]

26. Khan, U.; Adnan; Ahmed, N.; Mohyud-Din, S.T. 3D Squeezed Flow of $\gamma \mathrm{Al}_{2} \mathrm{O}_{3}-\mathrm{H}_{2} \mathrm{O}$ and $\gamma \mathrm{Al}_{2} \mathrm{O}_{3}-\mathrm{C}_{2} \mathrm{H}_{6} \mathrm{O}_{2}$ Nanofluids: A Numerical Study. Int. J. Hydrogen Energy 2017, 42, 24620-24633. [CrossRef]

27. Ahmed, N.; Adnan; Khan, U.; Mohyud-Din, S.T. Unsteady radiative flow of chemically reacting fluid over a convectively heated stretchable surface with cross-diffusion gradients. Int. J. Therm. Sci. 2017, 121, 182-191. [CrossRef]

28. Khan, U.; Adnan; Ahmed, N.; Mohyud-Din, S.T. Heat Transfer Enhancement in Hydromagnetic Dissipative Flow Past a Moving Wedge suspended by H2O-Aluminum Alloy Nanoparticles in the Presence of Thermal Radiation. Int. J. Hydrogen Energy. 2017, 42, 24634-24644. [CrossRef]

29. Ahmed, N.; Adnan; Khan, U.; Mohyud-Din, S.T. Influence of an Effective Prandtl number Model on Squeezed Flow of $\gamma \mathrm{Al}_{2} \mathrm{O}_{3}-\mathrm{H}_{2} \mathrm{O}$ and $\gamma \mathrm{Al}_{2} \mathrm{O}_{3}-\mathrm{C}_{2} \mathrm{H}_{6} \mathrm{O}_{2}$ Nanofluids. J. Mol. Liq. 2017, 238, 447-454. [CrossRef]

30. Timofeeva, E.V.; Routbort, J.L.; Singh, D. Particle shape effects on thermophysical properties of alumina nanofluids. J. Appl. Phys. 2009, 106, 14304. [CrossRef]

31. Khan, U.; Ahmed, N.; Mohyud-Din, S.T. Heat transfer effects on carbon nanotubes suspended nanofluid flow in a channel with non-parallel walls under the effect of velocity slip boundary condition: A numerical study. Neural Comput. Appl. 2015, 28,37-46. [CrossRef]

32. Devi, S.S.U.; Devi, S.A. Numerical investigation of three-dimensional hybrid Cu-Al2O3/water nanofluid flow over a stretching sheet with effecting Lorentz force subject to Newtonian heating. Can. J. Phys. 2016, 94, 490-496. [CrossRef]

33. Khan, U.; Ahmed, N.; Mohyud-Din, S.T. Thermo-diffusion, diffusion-thermo and chemical reaction effects on MHD flow of viscous fluid in divergent and convergent channels. Chem. Eng. Sci. 2016, 141, 17-27. [CrossRef]

34. Motsa, S.S.; Sibanda, P.; Marewo, G. On a new analytical method for flow between two inclined walls. Numer. Algorithms 2012, 61, 499-514. [CrossRef]

35. Turkyilmazoglu, M. Extending the traditional Jeffery-Hamel flow to stretchable convergent/divergent channels. Comput. Fluids 2014, 100, 196-203. [CrossRef]

(C) 2020 by the authors. Licensee MDPI, Basel, Switzerland. This article is an open access article distributed under the terms and conditions of the Creative Commons Attribution (CC BY) license (http://creativecommons.org/licenses/by/4.0/). 